\title{
LAS FECHAS DE EL FAETONTE, DE CALDERÓN
}

\author{
Luis Iglesias Feijoo y Alejandra Ulla Lorenzo \\ Departamento de Filología Española \\ Facultad de Filología \\ GIC-Universidad de Santiago de Compostela \\ Burgo de las Naciones \\ 15771 Santiago de Compostela. España \\ feligles@usc.es \\ alexul3@hotmail.com
}

[Anuario calderoniano (ISSN: 1888-8046), 3, 2010, pp. 173-198]

No todas las obras de Calderón han gozado del mismo interés por parte de los estudiosos ${ }^{1}$. Es lógico que las más famosas, aquellas que le aseguran un puesto de primera línea en la dramaturgia universal, hayan concentrado la atención, pero en los últimos años parece haber tomado impulso el deseo de revisar el conjunto de su teatro, sin desdeñar aquellos sectores considerados antes como secundarios o dotados de menor importancia. Uno de ellos es el de tema mitológico,

${ }^{1}$ Este trabajo se enmarca en el Proyecto de Investigación de la DGICYT dirigido por Luis Iglesias Feijoo HUM2007-61419/FILO, y en el Proyecto ConsoliderIngenio CSD2009-00033 sobre «Patrimonio teatral clásico español» TECE-TEI. 
sobre el que hubimos de fijarnos en el Grupo de Investigación Calderón (GIC), en el curso del trabajo de edición de los tomos de la Biblioteca Castro $^{2}$, en especial al preparar el segundo, el tercero y el cuarto.

Nuestra intención inicial fue la de atender al texto de la "comedia famosa» El Faetonte, incluida en este último volumen, pues presenta problemas hasta ahora no resueltos. Las pocas ediciones publicadas desde el siglo XIX han solido seguir la versión ofrecida por Vera Tassis en 1688, a veces relegada en favor de la Cuarta Parte de Comedias original (1672), como dicen hacer Valbuena Briones y Maestre ${ }^{3}$. Sólo la reciente aparición de esa parte, preparada por Sebastian Neumeister ${ }^{4}$, permite al fin conocer la obra en una versión mucho más próxima al original, pues en ella se atiende por primera vez a las lecturas que presentan algunos de los manuscritos antiguos hoy conservados, que mejoran notablemente el texto.

Sin embargo, resulta dificil exponer el complejo proceso de transmisión de la comedia sin plantear previamente el no menos arduo de su fecha de redacción, el de sus representaciones en vida de don Pedro y, en fin, el de la posibilidad de que él mismo hubiera procedido a revisarla alguna vez. Por lo tanto, ceñiremos hoy nuestro trabajo a estos problemas cronológicos, que, como se verá, trascienden el de la simple datación de la obra; a tal fin, aprovechamos lo avanzado en diferentes estudios, algunos muy recientes, para ofrecer una ordenación coherente. Queden, pues, para otra ocasión futura el examen de las

${ }^{2}$ El GIC, dirigido por Luis Iglesias Feijoo, se propone publicar todas las comedias calderonianas. Su distribución en los diversos volúmenes respeta la de las Partes impresas originalmente en el siglo XVII. El tomo segundo estuvo a cargo de Santiago Fernández Mosquera y el tercero de Don Cruickshank.

${ }^{3}$ Véanse las ediciones de Valbuena Briones de Obras completas. Dramas, de Calderón, 1959 y 1966, y la de El Faetonte de Maestre, 1996. Respecto de las de Valbuena, ya se ha señalado en alguna ocasión (Iglesias Feijoo, 2010, p. 88, n. 16) que, aunque se presentan como $4^{a}$ y $5^{a}$ de la serie de Aguilar, en realidad habían sido precedidas de cuatro ediciones del tomo de Dramas de Astrana Marín: 1932; $2^{a}$ ed. revisada, 1941; $3^{\mathrm{a}}$ ed. revisada, 1945; y de nuevo $3^{\mathrm{a}}$ ed. [no indica 'revisada'], 1951.

${ }^{4}$ Calderón de la Barca, 2010. Neumeister señala en su introducción, p. XIII, la fecha de 1 de marzo de 1661 como estreno de El Faetonte, de acuerdo con la idea generalmente aceptada; debe quedar claro que el presente trabajo se ha escrito después de que nuestro amigo y colega el profesor Neumeister hubiese entregado el original del volumen en 2009. 
variantes textuales que, en cualquier caso, cabe adelantar ya que exceden con mucho el centenar de lugares, y ello si se atiende solo a los sustanciales.

El primer intento de fechar El Faetonte debe ser atribuido a Hartzenbusch, quien la edita en el tomo IV de su colección; allí la adscribe en su "Catálogo cronológico»" a los años 1638-1639, al igual que hace con la que llama su primera parte, Apolo y Climene. Se basaba para ello en el hecho de que, según la versión de Vera Tassis que sigue, Tetis aparece en un carro marino, por lo cual supone que se trata del mismo que se empleó en El mayor encanto, amor; El Faetonte, según su razonamiento, debió de ponerse en escena en el estanque del Retiro y a esta última comedia cree que deben de referirse las alusiones que Pellicer y León Pinelo hacen a una obra, cuyo título omiten, que se hizo en efecto sobre el agua en junio de 1639 y que hubo de suspenderse por la borrasca que se levantó de repente, aunque la representación tuvo lugar pocos días después. Por cierto que estas deducciones aparecidas en el volumen IV de la BAE en 1850 corrigen lo apuntado dos años antes en el tomo I, en el que se atribuyen esas noticias de la tempestad de 1639 al montaje de El mayor encanto ${ }^{6}$.

La hipótesis de Hartzenbusch es insostenible, pese a ser asumida por estudiosos como Pierre Paris ${ }^{7}$. La razón no estriba en lo apuntado por Maestre en su edición ${ }^{8}$, quien sostiene que Calderón decidió prescindir del carro de la diosa Agua que preveía Cosimo Lotti cuando se representó El mayor encanto, amor ${ }^{9}$, pues el italiano planteaba esa salida para dar paso a la loa, que ignoramos si se realizó según sus indicaciones. Como fuere, en el estreno que se hizo en 1635 en el estanque del Retiro, según señala el índice de la primera edición de la Segunda Parte $(1637, \llbracket 2 r)$, sí se utilizó un carro marino cuando al final aparece Galatea: «Serénese el mar y sale por él en un carro triunfal Galatea; tíranle dos sirenas y alrededor muchos tritones con ins-

${ }^{5}$ Hartzenbusch, IV, p. 673.

${ }^{6}$ Hartzenbusch, I, p. 385.

7 Paris, 1925.

${ }^{8}$ Maestre, 1996, p. XIV, nota 7.

${ }^{9}$ El memorial de Cosimo Lotti lo reproduce Hartzenbusch en I, p. 387 para lo que nos ocupa acerca del carro, tomándolo de Casiano Pellicer, 1804, II, pp. 147-148. Sobre los cambios que realizó Calderón respecto a las indicaciones de Lotti, véase Fernández Mosquera, 2008, donde se resumen aportaciones anteriores. 
trumentos $»^{10}$. Por lo tanto, en teoría este carro efectivamente construido en 1635 pudiera haberse empleado cuatro años después... de existir la costumbre de conservar los elementos de escenografía y atre$z z o$, como hacen los grandes teatros modernos y como es casi seguro que no se hacía en el XVII.

El argumento de más peso a la hora de descartar una fecha temprana como 1639 reside en la versificación. Aunque sabemos que el uso de la métrica para sugerir la fecha de escritura de una obra dista de ser infalible, el análisis de Morley y Bruerton sobre las comedias de Lope de Vega demostró ser un instrumento muy útil y obtuvo el respaldo que supuso el descubrimiento del manuscrito Gálvez en 1945. Es indudable que en un corpus más reducido como el de Calderón las dificultades se incrementan, pero el trabajo de Hilborn, con todos los reparos que quieran hacérsele, sigue siendo un instrumento muy eficaz $^{11}$. Al respecto, un porcentaje de romance del $80 \%$, como el que presenta El Faetonte, que en realidad, según nuestro cómputo se eleva incluso al 83\%, responde a los usos calderonianos a partir de 1650. Es verdad que el propio Hilborn ofrece algún caso anterior, pero son descartables por diversos motivos, que sería prolijo enumerar ${ }^{12}$.

A corroborar una fecha más tardía vinieron los estudios de Emilio Cotarelo, que en su biografía de don Pedro indicó como estreno de la obra el año 1661, aceptado generalmente desde entonces: «El día de Carnaval, $1^{\circ}$ de marzo del año siguiente, 1661, se representó a los Reyes en el Buen Retiro una gran comedia de Don Pedro CalDERÓN, que exigió ensayos desde el 13 de febrero. Había de estrenarse el 28; pero por no estar bastante ensayada se puso el día siguien-

10 Ed. Fernández Mosquera, 2007, p. 103.

${ }_{11}$ Para Lope, véase Morley y Bruerton, 1968; para Calderón, Hilborn, 1938.

${ }^{12}$ En concreto, El privilegio de las mujeres (1636) ofrece un $87 \%$ de romance, pero don Pedro solo escribe una jornada (Hilborn, p. 20). El acaso y el error (atribuida al periodo 1633-1636; Hilborn, pp. 21 y 33-34), con su 81\% de romance, es posiblemente (como apunta Cruickshank, en prensa) una obra posterior a 1650, segunda versión de La señora y la criada, representada en 1635, que tiene un $62 \%$ de romance (véase también Romero Blázquez, 2007, aunque no compartimos la datación ahí propuesta). La adscripción de Las manos blancas no ofenden al año 1640 (Hilborn, p. 42) se basa en motivos muy indirectos y dudosos y no convence, como señala Martínez Blasco, 1995, en su edición, p. 76. Por lo tanto, la primera comedia que presenta un $80 \%$ de romance resulta ser Darlo todo y no dar nada, de 1651 (Hilborn, p. 51). 
te» ${ }^{13}$. Los datos, que se extienden a la mención de las dos compañías que actuaron - las de los autores Juana de Cisneros y Diego Osorio de Velasco-, procedían de la documentación localizada veinte años antes por Pérez Pastor ${ }^{14}$. Sin embargo, éste no identificaba la obra como El Faetonte, sino que resumía o transcribía el texto de los legajos, donde se señalaba que se trataba de «la fiesta grande a S. M. en el Retiro"; la citada Juana de Cisneros hablaba el 16 de febrero de demoras en los planes previstos, «según lo atrasada que estaba en las tramoyas y ensayos la fiesta grande y haber de hacer otra comedia su compañía para uno de los días de Carnestolendas a su Majestad, que es de Don Pedro Calderón, que hasta ahora no se la ha entregado...».

El día 28, la misma autora expresa que se fue al Retiro «a ensayar la comedia de D. Pedro Calderón que ha de hacer mañana martes a Su Majestad [...] y que aunque había de ser hoy lunes no se podía representar por no estar acabada de estudiar», y el día 1 de marzo vuelve a declarar que se va al Retiro «a ensayar una comedia de D. Pedro Calderón y los sainetes della, que se ha de hacer esta noche a $\mathrm{Su}$ Majestad». Así pues, queda claro que lo entonces planeado era realizar dos montajes teatrales: uno, la "fiesta grande», que tenía tramoyas y cuyo autor no se menciona, y otro la "comedia» de Calderón, que tenía que ser nueva, porque no la había entregado aún el día 16, razón por la cual tuvo que aplazarse del 28 de febrero al primero del mes siguiente. Fue, pues, Cotarelo quien identificó la obra de tramoyas con El Faetonte, y señaló que en el mismo día y lugar se hizo «otra comedia» de Calderón, que sugiere pudiera ser El castillo de Lindabridis, lo que no pasa de mera lucubración sin base documental.

Ahora bien, de las noticias editadas por Pérez Pastor no cabe deducir que ninguna de las dos pudiese ser El Faetonte, ni siquiera que la fiesta de tramoyas hubiese sido escrita por don Pedro, aunque el silencio respecto a su autoría tampoco es una prueba en contra. Antes bien, es sabido que por entonces Calderón se había convertido en el dramaturgo casi oficial de la corte y a él se recurría para las obras que

13 Cotarelo, 1924, p. 313. Repite la fecha sin comentarios en Cotarelo, 1934, p. 58, aunque ahí rectifica la de alguna otra obra. Stein, 1993, p. 169, asume también que tanto Apolo y Climene como El Faetonte se estrenaron en los carnavales de 1661.

14 Pérez Pastor, 1905, pp. 280-281. Normalizamos la ortografía en el texto citado luego, al igual que en todos los documentos que se mencionan. 
se representaban con motivo de festejos y cumpleaños. En 1651 escribió Darlo todo y no dar nada para el cumpleaños de la reina, en palacio; en 1652 La fiera, el rayo y la piedra para el Retiro; en 1653 Andrómeda y Perseo para el mismo lugar; en 1657, El golfo de las sirenas para la Zarzuela; en 1658, Afectos de odio y amor y El laurel de Apolo, ambas en el Retiro en marzo, y Los tres afectos de amor en noviembre en el mismo lugar; en 1659, En la vida todo es verdad y todo mentira; en 1660, La púrpura de la rosa, estrenada en enero, Mujer, llora y vencerás con otras dos suyas desconocidas para los días de Carnaval y Celos aun del aire matan en diciembre, escrita para el cumpleaños del príncipe Felipe Próspero ${ }^{15}$. Por ello, nada tiene de extraño que esa fiesta de tramoyas de 1661 sea obra de Calderón, como vamos a ver luego.

La deducción de Cotarelo al identificar la comedia grande de marzo con El Faetonte no pasa, pues, de ser una ingeniosa conjetura, que implica además un error, ya que la representada el primero de ese mes fue la que el 16 de febrero aún no estaba entregada y que seguimos sin saber cuál fuese. Las circunstancias que rodearon el montaje de estas obras preparadas para el Carnaval de 1661 son hoy mucho mejor conocidas. Para aclarar los datos conviene tener en cuenta las fechas de otras creaciones del autor. La primera es la citada Celos aun del aire matan. El estreno se produjo en Palacio el 5 de diciembre de 1660, tras bastantes días de ensayos que habían dado lugar a que se cesase de representar en los corrales. En principio se había previsto hacerla el 28 de noviembre, cumpleaños de Felipe Próspero, pero se aplazó «por lo mucho que tenía que hacer... hasta que se sepa bien» y en su lugar se dio una comedia vieja de Moreto. La fiesta, que era «toda cantada», sigue ocupando a las compañías de Diego Osorio y Juana de Cisneros, que ensayan "mañana y tarde» con sus músicos y los de la capilla real; Calderón asistía algunos días, quizá de forma permanente. Al fin, la misma mañana del día 5 apuran los ensayos y a la tarde el escribano que indaga por qué no se abren los corrales ve entrar a los actores para hacer la función ${ }^{16}$.

${ }^{15}$ Ver una relación de las obras teatrales con música de estos años — no sólo las de Calderón, que son la mayoría - en el apéndice de Cruickshank a la edición de La púrpura de la rosa (1990, pp. 513-521).

16 Pérez Pastor, 1905, pp. 277-279. Lobato, 2002b, p. 245, recoge la noticia que da el embajador toscano del estreno el 5 de diciembre de la "commedia in musica 
Una obra de Calderón «toda cantada» sólo podía ser La púrpura de la rosa o Celos aun del aire matan. A veces se ha supuesto que la obra representada ese día era una reposición de la primera, ya estrenada el 17 de enero de ese año. Esa fue la sugerencia inicial de Cotarelo, pero la corrigió unos años después, lo que no siempre fue atendido por los estudiosos ${ }^{17}$. Es cierto que una comedia podía ser repuesta semanas o meses más tarde, pero, si se hubiese tratado de La púrpura, no se explican demasiado bien las dificultades que las compañías de Osorio y la Cisneros sufrieron para poder montarla y que exigieron tantos ensayos. En enero de 1660 había estado a cargo de otras dos, las de Pedro de la Rosa y Juan de la Calle-Sebastián de Prado, y este último se había marchado en abril con sus actores a París en la comitiva de María Teresa de Austria tras su matrimonio con Luis XIV, por lo que faltarían en diciembre algunas de las actrices-cantantes que intervinieron en el estreno: la mayoría de los personajes, tanto masculinos como femeninos, estaban encarnados en las obras musicales por mujeres. Sin embargo, en Madrid habían permanecido otras tan significadas como María de Quiñones, Francisca Bezón (la Bezona), Micaela de Andrade y sus hermanas Ana y Feliciana (las Tenientas), Mariana y Luisa Romero, María de Salinas, Mariana de Borja (la Borja) o María y Manuela de Escamilla, algunas de las cuales trabajaban regularmente con Osorio y otras pudieron ser añadidas para hacer esta función, según era costumbre practicada de ordinario por el marqués de Heliche, aparte de las que aportaba la Cisneros, llamada desde Sevilla, como Josefa Pavía ${ }^{18}$.

Como ha visto muy bien Cruickshank, La púrpura es una obra corta, de algo menos de 1.500 versos sin la loa, en la cual se la define como «una pequeña / representación»: «No creemos que una segunda representación de La púrpura de la rosa pudiera causar tantas difi-

con macchine». Chaves Montoya, 2004, pp. 281 y 315, la recoge también y añade el aviso coincidente de la nunciatura.

17 Cotarelo, 1924, pp. 311-312; Shergold, 1967, pp. 324-325; Chaves Montoya, 2004 , p. 281. Pero Cotarelo, 1934, p. 52, n., rectifica explícitamente su primera deducción y señala que la estrenada el 5 de diciembre fue Celos aun del aire matan.

18 En el Corpus de 1660 Juana de Cisneros había hecho uno de los autos en Sevilla (Sánchez Arjona, 1898, p. 426); en su compañía estaba Josefa Pavía, quien, según la Genealogía, «cantaba muy bien» (ed. Shergold y Varey, 1985, p. 445). Para todas 
cultades» ${ }^{19}$. Por lo tanto, la obra representada el 5 de diciembre de 1660 hubo de ser Celos aun del aire matan, dividida en tres actos y que supera los 2.400 versos. Ahora bien, montada entonces en Palacio, se pensó repetirla en Carnavales en el Retiro, y aunque se planeó en principio para el Salón, pudiera luego pasarse al Coliseo, dotado de medios que podían hacerla más espectacular y susceptible de ser ofrecida asimismo al público general. Reiterar una comedia en fecha tan cercana no era por cierto algo insólito: en 1657, tras estrenar El golfo de las sirenas el 17 de enero en la Zarzuela, se repuso el 12 de febrero en el Retiro ${ }^{20}$, y algo parecido había ocurrido en los carnavales del año anterior de 1656, cuando Pico y Canente, de Luis de Ulloa y Rodrigo Dávila pasó del Salón del Retiro al Coliseo del mismo lugar $^{21}$; lo mismo sucedería más tarde en 1662 con Psiquis y Cupido.

Pero antes de llegar a la reposición de Celos hay que atender a la puesta en escena de otra obra en el teatro de la Zarzuela el 24 de enero del mismo 1661, de la que dan cuenta los embajadores italianos, que la definen como «una commedia parte in musica et parte recitata, composta espressamente per tal soggeto dal poeta Calderón». Aunque Chaves sugería que pudiera tratarse del reestreno de El golfo de las sirenas, parece dificil que a esta se le pudiera aplicar la frase de 'compuesta expresamente a tal fin' por don Pedro ${ }^{22}$. En este momento es necesario recordar la extraña falta de noticias que hay en esos años sobre el estreno de Apolo y Climene, que por fuerza debió de tener lugar antes del de El Faetonte, anunciada en sus últimos versos. Por lo tanto, es probable que la comedia del 24 de enero, interpretada por

las noticias referentes a los actores es ahora indispensable la consulta del DICA de Teresa Ferrer.

${ }^{19}$ Cruickshank, ed. de La púrpura de la rosa, 1990, p. 41. De la misma opinión es Lobato, 2002b, p. 245, aunque sitúa el estreno de Celos en el Retiro. Stein, 1993, pp. 219-220, también venía a sostener lo mismo, con algunas dudas. Mantienen asimismo la fecha del estreno de Celos el 5 de diciembre de 1660 Stroud, en su edición de la obra, 1981, p. 22, o Tobar, 2000, p. 21.

${ }^{20}$ Varey y Shergold, 1973, pp. 222 y 223; pueden verse también las anotaciones de Barrionuevo al respecto en Díez Borque, 1995, p. 291.

21 Chaves Montoya, 2004, p. 225.

22 Chaves Montoya, 2004, pp. 286 y 316-317, n. 95. En comunicación particular reciente, que agradecemos, María Teresa Chaves indica que hoy en día no mantiene la identificación de esa obra con El golfo de las sirenas. 
las mismas compañías de Osorio y la Cisneros, hubiese sido, en efecto, Apolo y Climene ${ }^{23}$.

Se llega así a los complicados preparativos para las fiestas de Carnaval. Para esos días los Reyes se trasladaban al Palacio del Buen Retiro y se sucedían las representaciones teatrales. Este año de 1661 en concreto se preparaban tres comedias y la «fiesta grande». La primera se puso en escena el sábado 26 por la compañía de Escamilla, mientras los entremeses y piezas breves estaban a cargo de las de Osorio y la Cisneros; se trataba de Fingir y amar, «de tres ingenios», según los documentos conservados, aunque se le atribuye solo a Moreto en la edición que se hizo de inmediato, al incluirse en el tomo 15 de Escogidas ${ }^{24}$. Para el domingo 27 estaba prevista la «fiesta grande», que no llegó a hacerse, como vamos a ver, por lo que Osorio montó la segunda comedia, cuyo autor ignoramos. La tercera comedia era la desconocida de Calderón, que Juana de Cisneros declaraba el 16 de febrero que aún no se la había entregado, como ya vimos; es seguro que se preveía para el lunes de Carnaval, día 28, pero tuvo que retrasarse para el día siguiente, primero de marzo, por no estar bien preparada ${ }^{25}$.

${ }^{23}$ La obra estuvo en ensayos desde el día 8 (Varey y Shergold, 1973, p. 235); las «bajas» del arrendador de los corrales, que reclama por los días en que estos tuvieron que cerrar por ser convocadas las compañías para actuar en los sitios reales y que publicaron Varey y Shergold, 1973, pp. 158-160 y 235-236, nos informan de que, desde el 21 de diciembre de 1660 hasta el 1 de marzo del año siguiente los cómicos abandonaron los corrales durante 37 días para ensayos o representaciones en el Pardo, en la Zarzuela, para la fiesta de cumpleaños del príncipe, para «la fiesta grande del Retiro» y para "las tres comedias de los cuatro últimos días de carnestolendas». Hubo comedias en Palacio el 22 de diciembre y el 2 de enero y en el Pardo el 16, el 20 y el 27 de enero. Desconocemos de qué obras se trataba.

24 Se menciona Fingir y amar en Varey y Shergold, 1973, p. 235. La comedia se publicó el mismo año de 1661; el volumen lleva la aprobación más temprana del 12 de mayo. Parece extraña una impresión tan cercana al estreno, pero pudiera no ser una comedia recién escrita: en diciembre de 1660 se la cita con alguna tan antigua como La puente de Mantible (Pérez Pastor, 1905, p. 266); quizá se trate de dos obras con el mismo título, una de Moreto y otra de tres ingenios, pero es poco probable.

25 Cruickshank, en el apéndice a la edición de La púrpura de la rosa, 1990, p. 520, sugiere que la obra estrenada el 1 de marzo pudiera ser Apolo y Climene, aunque reconoce que no hay pruebas de ello; también Neumeister, 2000, p. 314, la sitúa en los carnavales de ese año. Como tiene parte cantada, que, según Cruickshank, ocupa el 
Hoy es bien conocida la causa del aplazamiento de la "fiesta grande», con tramoyas y música, que el secretario toscano definía como «una festa teatrale in musica» ${ }^{26}$ y precisaba que se preparaba para el salón del Retiro. Se trataba de la reposición de Celos aun del aire matan, a cargo de las dos mismas compañías que la habían estrenado (Osorio y Cisneros), probablemente con idéntico reparto, por lo que no hubo de plantear tantos problemas, excepto el de hacerse con el manejo de las máquinas escénicas en el Coliseo del Retiro, para lo cual venían ensayando desde días antes, aunque con poca premura, por lo que el 16 Juana de Cisneros se lamentaba de «lo atrasada que estaba en las tramoyas y ensayos la fiesta grande». Pero el 22 la actriz Luisa Romero sufrió un accidente al caerse precisamente de una de las tramoyas, como descubrieron Varey y Shergold al consultar la misma documentación utilizada por Pérez Pastor ${ }^{27}$.

En principio, el percance no parecía frustrar el espectáculo, pues se improvisó una sustitución y el 25 la cómica había sido reemplazada por «Gaspar, el músico de la compañía de Osorio» — que podía ser Gaspar Real-, en el ensayo general «con todas las tramoyas y luces». Pero la Romero no interpretaba un papel cualquiera, sino el del protagonista Céfalo ${ }^{28}$, por lo que su dificultad debió de ser excesiva para el sustituto; la correspondencia de los embajadores italianos publicada por Chaves demuestra que finalmente el montaje hubo de suspenderse de manera definitiva hasta después de la Pascua ${ }^{29}$. Así, desde finales de mayo se retomaron los preparativos para poner en escena Celos... en el Retiro, lo que al fin se logró el 6 de junio ${ }^{30}$. Pero en el intervalo

3’3\% del texto, ya quedó expresada nuestra opinión de que pueda ser la "parte in musica et parte recitata» del 24 de enero.

26 Chaves Montoya, pp. 287 y 317, n. 103.

27 Varey y Shergold, 1973, p. 236.

28 Decía el secretario toscano el 2 de marzo: «cadete da una macchina andante con pericolo della vita una donna che faceva il primo personaggio in detta festa" (Chaves Montoya, pp. 204 y 317, n. 101). Es posible que el accidente se produjera al final, cuando Céfalo asciende con Pocris y Aura; véase la ed. de Rull, 2004, p. 204.

${ }^{29}$ Chaves Montoya, 2004, pp. 287 y 317, n. 104: el último día de Carnaval sus majestades retornaron a palacio, donde se representaron dos comedias, «non essendosi potuto finire de metter in ordine quella che con molta apparenza di machine si sta disponendo al ritiro, et se ne differirà perciò lo spettacolo per dopo Pasqua».

30 Chaves Montoya, pp. 288 y 317, n. 109: «Si cominciò l'altro hieri a rappresentare l'opera in musica chiamata Pocri nel gran teatro del Retiro", nota de la nun- 
se había producido el regreso desde París de la compañía de Sebastián de Prado, de manera que pudo echarse mano de algunas de sus actrices-cantantes. El reparto publicado en la primera edición de la obra, que se imprimió poco después, es el de esta representación, que sin duda hubo de ser mucho mejor que la del estreno seis meses antes. En escena se sumaron actrices de diversas compañías, desde la misma Luisa Romero, accidentada en febrero, hasta Josefa Pavía, que había venido de Sevilla con la Cisneros, pasando por Bernarda Manuela (la Grifona), María de Anaya, María de los Santos y Bernarda Ramírez, las cuatro venidas muy probablemente de Francia con Prado y la última de las cuales moriría pocos meses después, en octubre ${ }^{31}$. A ellas se sumaron gentes de la compañía de Escamilla — con el propio autor a la cabeza-, como su hija Manuela o la Borja ${ }^{32}$.

Calderón siguió aplicado a la redacción de textos para las fiestas reales. Poco después, en julio de 1661, se estrenó Eco y Narciso en el Retiro y comenzó luego a preparar otra obra para celebrar el nuevo parto de la reina, esperado para otoño. Su puesta en escena se vio, sin embargo, alterada por el imprevisto fallecimiento del príncipe Felipe Próspero el 1 de noviembre, solo paliado por el nacimiento de otro heredero, el futuro Carlos II, que tuvo lugar el día 6 . Aunque las representaciones en los corrales se reanudaron ya el 7 , no hay noticia de que se hubiera hecho lo mismo con las fiestas reales, que esperarían a la recuperación de la reina, quien salió a dar gracias a la Virgen de Atocha el 19 de diciembre, ocasión en que se repuso Eco y Narciso en

ciatura del día 8 de junio. El día 1 de junio el secretario toscano había avisado de la próxima representación de la «Commedia in musica che si sta preparando da più mesi in qua» (Chaves Montoya, p. 317, n. 108).

31 Subirá, 1960, pp. 75-76, no acaba de explicarse cómo en el reparto de la primera edición figura Bernarda Ramírez, si en diciembre de 1660 estaba en Francia, por creer que los actores mencionados eran los del estreno, en vez de los de la representación de junio de 1661; por cierto que su indicación de que ella cantó el papel de Floreta, «como se puede ver en mi transcripción musical del acto primero, cuyo manuscrito descubrí en el Palacio de Liria» (p. 75) parece sugerir que en él se señalaban los actores que intervenían, pero en su edición de la música no los indica (Subirá, 1933).

${ }^{32}$ Véase la ed. de Rull, 2004, p. 143; el reparto completo se publicó en la primera edición de la obra, en la Parte 19 de Escogidas (1663), que tiene licencias de octubre de 1662. 
el Ayuntamiento ${ }^{33}$. Hubo, pues, que esperar a enero de 1662, pero en el intervalo se produjo asimismo el 16 de noviembre el fallecimiento del valido, don Luis Méndez de Haro, que conllevó el cese de su hijo el marqués de Heliche como organizador de los festejos del Retiro y su sustitución por el duque de Medina de las Torres. Este ordenó los preparativos para el asentamiento de los reyes en el palacio del Buen Retiro, que solía extenderse desde mediados de enero hasta el fin de los Carnavales.

La primera fiesta teatral que se representó fue Psiquis y Cupido, de Calderón, es decir, Ni Amor se libra de amor, el 19 de enero de 1662. Y para los Carnavales se preparó el montaje de El Faetonte, lo que se constata por las actas del proceso que se instruyó con motivo de un intento de prender fuego al Coliseo del Retiro, promovido por el despechado marqués de Heliche al haber sido privado de sus competencias en el real sitio. El 14 de febrero, al ir a trasladar unas tramoyas desde el teatro al Salón donde había de hacerse el estreno (entre otras la que debía mover el carro de Faetón), se descubrió una mecha consumida, palos embreados y pólvora, que habían de provocar el incendio del recinto ${ }^{34}$. El frustrado atentado no interrumpió los festejos, y el 20 de febrero se puso en escena El Faetonte en el Salón ${ }^{35}$. Un continuador de Barrionuevo la definió como "comedia grande [...] con muchas mutaciones de tramoyas» y la nunciatura escribió a Roma el 22: «Si rappresentò l'altra sera nella Sala del Ritiro la Commedia della Caduta di Faetonte con molte macchine» ${ }^{36}$.

Chaves sostiene con toda razón que esta no fue una reposición de la obra, sino su primer estreno, pero insinúa que pudo estar prevista para una ocasión anterior. No es descartable que se tratara, en efecto, de la obra preparada el año precedente para el cumpleaños del príncipe o para celebrar el nuevo parto de la reina, pero nada lo prueba y la loa de la obra que figura en uno de los manuscritos antiguos y

${ }^{33}$ Varey y Shergold, 1973, p. 238.

34 Shergold, 1967, pp. 325-326; Chaves Montoya, pp. 293-294. Ya Varey, 1957, p. 211, había señalado los documentos del incendio y su relación con la fecha de $E l$ Faetonte, corrigiendo la propuesta por Cotarelo.

35 Cotarelo, 1924, pp. 314-315, menciona la existencia de una comedia de Calderón el 20 de febrero, pero ignora de cuál se trata; no se olvide que, para él, El Faetonte se había representado el año anterior.

36 Chaves Montoya, pp. 295 y 320, n. 139. 
que fue publicada por primera vez por Neumeister ${ }^{37}$ ha sido mal interpretada. Se trata de una copia de la Biblioteca Nacional de España (ms. 16.539), a la que Paz y Mélia ${ }^{38}$ atribuye por motivos erróneos letra de fines del siglo XVIII, y que tiene mucha mayor importancia de la hasta ahora concedida, como vamos a ver. La loa, adjudicada ahí al mismo Calderón, contra lo señalado a veces ${ }^{39}$, tuvo que ser escrita a fines del año 1661 o comienzos del siguiente, lo mismo que la comedia. En ella se hace referencia a la enfermedad del nuevo heredero, que desde los primeros días dio muestras de muy endeble salud. Su comienzo cantado alude a la protección que «el austro» va a proporcionar a una «flor»: "A la sombra del laurel, / no temas, vasalla flor, / del cierzo el soplo cruel, / que presto vendrá el favor / del austro que inspira en él». Esta «letra / que suena a modo de enigma» y «que ocultos misterios cifra» se retoma en la parte ya hablada: «iAy de mí, si no mejora / del cierzo el austro las iras!». Se prevé un peligro que no se menciona más que por alusiones, que se hacen manifiestas al conocer la preocupación por la salud del príncipe, cuya mejoría se pronostica:

37 Neumeister, 1978, pp. 331. No se incluye en Neumeister, 2000. Tenemos en cuenta su edición, pero la citamos directamente del manuscrito, modernizando en lo oportuno grafias y puntuación. El texto del Faetonte se ha conservado en cuatro manuscritos del siglo XVII, aunque sin fecha, custodiados hoy en día en la Biblioteca Nacional de España (Reichenberger, 1979, t. III, pp. 300-301). Aparte del citado en el texto, se trata del Res. 120, que es uno de los copiados por Seudo Matos Fragoso, y del 16.399. El cuarto manuscrito, con fecha de 1762, se conserva en la Biblioteca Histórica Municipal de Madrid bajo la signatura Tea 1-74-10, y carece de valor textual.

38 Paz y Mélia, 1934, p. 204. Se trata de una caligrafia bastante adornada, no imposible en el siglo XVII. La razón de llevarla al siglo siguiente parece proceder de la atribución que hace de un baile que figura entre dos jornadas a don Jerónimo Cifuentes, "que escribió en 1750 la comedia: Lo que son suegro y cuñado», grave error, porque esta comedia se incluye en la Parte 18 de Escogidas, publicada precisamente en 1662. Debe señalarse que la portada del manuscrito reza: «Comedia famosa de $E l$ Faetón, hijo del Sol, de D. Pedro Calderón», mientras que la loa indica: «Loa para la comedia del Hijo del Sol, Faetón». El título que puso Vera Tassis no parece, pues, inventado por él, sino que era uno de los que tenía desde el principio.

${ }^{39}$ Ya Lobato, 2000, p. 372, y 2001, p. 200, había puntualizado que la loa es de Calderón. 


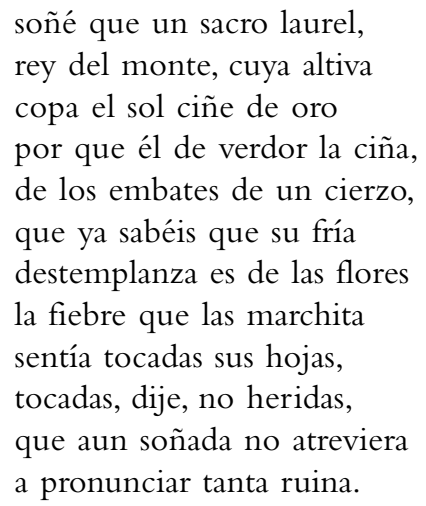

Rosas, azucenas y jazmines tiemblan ante la fuerza del cierzo, pero resurge la esperanza al ver que «el austro» se le opone.Y de ahí se desempeña toda una genealogía de la casa de Austria, que adquiere valor corpóreo, al señalar la acotación: "Corre la cortina y vese la galería con las estatuas». Se trata de una exhibición de las antiguas raíces de la estirpe, al modo de la serie de las veinticinco estatuas del jardín de los emperadores delante del antiguo Alcázar frente a la Torre Dorada o a la serie de los Doce Césares de Tiziano, comprados en 1652 en la almoneda de Carlos I de Inglaterra y que probablemente Velázquez, ya como aposentador mayor, acababa de disponer en la Galería del Mediodía del mismo recinto, sumándose a los retratos de Carlos I, la emperatriz Isabel y Felipe II a fin de entroncar a la dinastía con la Roma imperial ${ }^{40}$.

La aparición de la genealogía austríaca se produce «a fin de añadir en ella / al príncipe que nos viva / siglos eternos». De esa manera, con su protección renace la alegría, pues «festivo parabién / es de aquesa mejoría»; así se pronostica «tanta dicha / como añadir nuevo alumno / al Austria». Sigue, pues, la enumeración de los reyes y emperadores austríacos, que de improviso es interrumpida en el manuscrito tras mencionar a Felipe I y a Carlos $\mathrm{V}$ con un verso que queda trunco: «Yo lo diga», que inicia folio (fol. 6v) y va precedido al pie del folio anterior (6r) de otro verso añadido fuera de la caja de escritura: «sino por el quinto Carlos», indicios de una corrupción en la copia. No es ahora el momento de detenerse en los problemas textuales de

40 Orso, 1986, pp. 14 y 144-153; Checa, 1994, p. 400. 
la $\operatorname{loa}^{41}$, pues interesa llegar al momento en que la Dama Primera, que representa la Poesía, interrumpe el repaso de los monarcas austríacos y pronuncia:

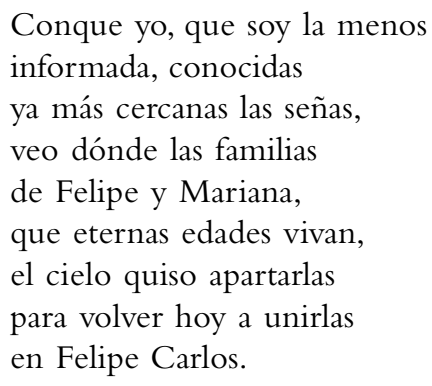

Queda ahí el octosílabo trunco otra vez y se retoma extrañamente la relación de los miembros de la casa de Austria con Felipe II, para acabarla con el emperador Fernando III, padre de la entonces reina de España Mariana. Y, acto seguido, la Dama Primera vuelve a decir los mismos versos que acabamos de reproducir, solo que introducidos por «Aunque yo» en vez de «Conque», y con un cambio en el último, para evitar la reiteración con lo que sigue en boca de la Dama Segunda, la Historia:

para volver hoy a unirlas en nuestro príncipe.

\section{Eso}

es lo que a tus pies me humilla, ¡oh, eterna Fama!, pidiendo que hoy en tus bronces escriba al quinto Felipe Carlos.

Por lo tanto, parece claro que el copista de la loa ha traspapelado las hojas del original de Calderón y copiado dos veces lo que parece

41 Maestre, 1996, advierte varios en su edición, pero no acaba de resolverlos. Ya en el paso del folio $5 \mathrm{v}$ al $6 \mathrm{r}$ hay otra anomalía, al crearse un octosílabo defectuoso: "¿Quién es este? - Maximiliano». Además se cita dos veces casi seguidas a este emperador, lo mismo que se hace también con Felipe el Hermoso, indicios todos de que en la copia hay un trastrueque de páginas del original dificil de resolver. 
sobrar en la primera ocasión, pues así se regulariza en parte la métrica y el sentido. La pieza termina con el regocijo ante «las nuevas de su salud» y la repetición del canto acerca de que el «austro» detendrá el rigor del cierzo. Esta mención al quinto Felipe Carlos ha sido tomada como una referencia a Felipe Próspero a partir de una indicación de Maestre en su edición ${ }^{42}$, lo que supondría que Calderón habría escrito el texto antes de su muerte, pero entre la casi docena de nombres que portó el príncipe no figuraba el de Carlos ${ }^{43}$. El aludido es en realidad el futuro Carlos II, que ignoramos si tenía también entre sus nombres el de Felipe ${ }^{44}$; sólo así se entiende la referencia citada a que es «nuevo alumno» de la casa de Austria, lo que sería incongruente de tratarse de Felipe Próspero, al que faltaba menos de un mes para cumplir los cuatro años cuando falleció.

Se daba así paso a la obra mayor: «a cuya causa traía / en festivo parabién / aquesta fábula escrita». El texto que presenta el manuscrito de referencia es mucho mejor que el de la edición aparecida en la Cuarta Parte de Calderón (1672), que no es mejorado, sino al revés, en la segunda edición de 1674. Pero ya quedó dicho que aquí no vamos a abordar los problemas textuales. Importa, en cambio, atender a las tres piezas breves que acompañan a El Faetonte en el mismo manuscrito que contiene la loa. Se trata del Entremés del hidalgo de la Membrilla, de Francisco de Avellaneda, al final de la primera jornada; el Baile de la Fiesta del Ángel de Cifuentes (Sifuentes, según la grafia que presenta), al acabar la segunda; y el Fin de fiesta para la comedia de Faetón de D. Francisco Antonio de Monteser ${ }^{45}$.

42 Maestre, 1996, p. 13; asumen la identificación sin discutirla Lobato, 2002b, p. 246; Chaves Montoya, 2004, p. 295, Cienfuegos Antelo, 2006, p. 147, y Farré, 2009, p. 169.

43 Según Rodrigo Méndez Silva, Gloriosa celebridad de España en el feliz nacimiento y solemnísimo bautismo de su deseado príncipe D. Felipe Próspero, Madrid, 1658, fol. 22v, le impusieron los nombres de Felipe, Próspero, José, Francisco, Ignacio, Antonio, Luis, Isidro, Ilefonso, Buenaventura, Domingo, Ramón, Diego y Víctor.

${ }^{44}$ Dice el Duque de Maura, 1990, p. 33, que al futuro Carlos II se le impusieron, además de ese, los nombres de «José, Joaquín, Leonardo y doce más». Contreras, 2003 , p. 48, añade los de Severo, Benito e Isidro y señala «hasta llegar a dieciséis». Podría también entenderse que, como cuatro reyes españoles de la casa de Austria que le habían precedido se habían llamado Felipe, Calderón quisiera llamar a Carlos «quinto Felipe».

45 Ya alude a esas tres piezas Lobato, 2001, pp. 200-201, y 2002a, pp. 338-339. 
Tal como a menudo ocurre con las piezas del teatro breve, los personajes están designados con los nombres de los actores que los encarnaban. Su examen prueba que, sin excepción, todos formaban parte de las compañías de Sebastián de Prado y de Antonio de Escamilla, que con la de José Carrillo fueron convocadas a la vez ${ }^{46}$ para encargarse de la representación celebrada el 20 de febrero de 1662. Como los actores de Carrillo no figuran en las piezas cortas, es de suponer que se hicieran cargo de casi toda la obra mayor; al propio autor, que lo era sólo desde el año anterior, según los datos acopiados por Teresa Ferrer ${ }^{47}$, se le definía en 1655 como "músico contralto», por lo que debía de asumir papeles que tuvieran partes cantadas.

Castro [Antonio de], Orozco [Miguel de], Alonso de Olmedo, Francisca Verdugo, María de Prado, Escamilla, Simón [Aguado], la Grifona [Bernarda Manuela], la Borja [Mariana de] y Micaela [de Andrade, mujer de Diego Osorio], así denominados, intervienen en la primera pieza breve, el entremés de Avellaneda; todos, salvo la Grifona están citados en las notificaciones expedidas el 21 de febrero de 1662 para que ningún actor saliera de la corte sin permiso ${ }^{48}$. Esa pieza breve, que tiene una reciente edición moderna ${ }^{49}$, termina con coplas en honor del nuevo príncipe: «A Carlos en palacio / solo le dejan, / y queda sin sus padres / cual digan dueñas».

El baile de Cifuentes, además de algunos actores que ya salían en la pieza anterior, presenta la actuación de la Bezona [Francisca Bezón], Carlos [Vallejo] y un Cruzado sin identificar; los dos primeros figuran en el citado expediente de 21 de febrero. Este baile tiene nuevas alusiones al recién nacido: «¿Y el principito? -Está en casa / ¿Cómo no sale? -Porque / no le dio licencia su ama»; y más adelante: «Al sol Carlos le vean / con dicha grande / que sea de las lunas / cuarto menguante. / Vaya de fiesta y baile, / que con nacer el niño / se ha visto el ángel».

Por último, en el fin de fiesta de Monteser vuelven a repetir algunos actores y además intervienen Manuela de Escamilla, Juan de la

${ }^{46}$ Ya lo señalaba, sin identificar las compañías, Pérez Pastor, 1905, p. 291. Varey y Shergold, 1973, p. 239, indican que se había hecho venir a la de José Carrillo desde Segovia y a la de Escamilla desde Toledo para que intervinieran en las fiestas reales.

47 Teresa Ferrer, 2008, s. v.

48 Shergold y Varey, 1961, p. 160.

49 Cienfuegos Antelo, 2006, pp. 147-160. 
Calle, Morales [Jerónimo de], María de Quiñones, Anaya [María de], la Santos [María] y Salinas. Este último nombre puede ser identificado con María Salinas y sería la única de la compañía de José Carrillo que actuó en las piezas $\operatorname{cortas}^{50}$; los demás están en el documento de febrero ya mencionado; y aparecen asimismo una Francisca Cuerda y un Luis, que acaso pudiera ser Luis de Mendoza. El texto de esta última pieza alude a las fiestas de Carnaval en que se representó: "Ya sabe como son Carnestolendas".

De todo lo expuesto se deduce una nítida conclusión: el texto del manuscrito de que tratamos reproduce la puesta en escena de El Faetonte que se llevó a cabo el 20 de febrero de 1662. Muchos de los actores que se citan en él continuaron actuando los años siguientes, pero fue precisamente en 1662 cuando se retiró Diego de Osorio con su mujer, Micaela de Andrade, por haber heredado un mayorazgo; en el citado expediente del 21 de febrero en que se instaba a los representantes a no abandonar Madrid ya declaran que los esposos «tratan de irse desta Corte a su tierra», y no actuaron más en los teatros. La copia pudo ser escrita poco después y posee, por lo tanto, una autoridad que hasta ahora no le ha sido reconocida.

Pero los festejos de Carnaval debieron de ser más amplios aquel 20 de febrero. En 1663 publicó Vicente Suárez de Deza y Ávila la Parte primera de los Donayres de Tersicore, que lleva aprobaciones del mes de marzo. En él se incluye un Sainete para el Coliseo del Buen Retiro. De los títeres, en la comedia de Faetón (fols. $35 \mathrm{r}-40 \mathrm{v})^{51}$. Es muy dificil que solo un año más tarde el autor hubiera equivocado el dato, lo que lleva a suponer que hubo otros entremeses y piezas breves antes o después de la obra de Calderón; ello no resultaba insólito: por ejemplo, en 1680 se representaron en Carnaval dos comedias y nueve entremeses $^{52}$. Y no deja de ser significativo que Suárez de Deza concluya con referencia a la familia real:

50 Teresa Ferrer, 2008, s. v. Carrillo

51 Habla de él Varey, 1957, pp. 211-212. Sigue sus pasos Buezo, 1993, I, p. 460. Está editado modernamente por Esther Borrego en Suárez de Deza, 2000, II, pp. 638656. Ver también Borrego Gutiérrez, 2002. Ya señaló que se había representado con El Faetonte Lobato, 1999, p. 107.

52 Shergold y Varey, 1982, p. 104. 
Pus con los títeres y

con él a los Reyes muesos

y al príncipe, que Dios guarde,

con la Anfantica y loceros

que la siguen...

Y terminan bailando: «Vivid y con Mariana / veáis logrado / deste Carlos Segundo / Quinto otro Carlos».

En los años inmediatos no hay noticias de nuevas puestas en escena de El Faetonte. Hay que esperar para hallarlas hasta mediados de los años setenta. En la nómina de los gastos que ocasionó la representación de Amado y aborrecido para celebrar los años de la Archiduquesa, el 18 de enero de 1676, se indica la compra del «orijinal de la comedia de Faetón» por un importe de 73 reales y medio, pagados «a quien la tenía ${ }^{53}$. La cantidad es muy elevada para tratarse de un impreso, aunque la obra había sido incluida en la Parte Cuarta del autor, que contaba ya con dos ediciones recientes (1672 y 1674), la primera de las cuales estaba tasada en 435 maravedíes, es decir, que no llegaba a los 13 reales — la otra costaba unos pocos maravedíes más-, mientras que lo abonado ascendía a 2.499 maravedíes, como ya notó Cruickshank ${ }^{54}$. Debía de tratarse, pues, de un manuscrito, acaso autógrafo, si atendemos al término "orijinal» con que se le designa. Acaso acababa de ponerse en escena la comedia o bien se preparaba un nuevo montaje para entonces. El documento inmediatamente anterior al referido a la compra del original de El Faetonte, que reproducen también Shergold y Varey ${ }^{55}$, señala la representación de una de una comedia en Palacio, con loa y bailes de Juan Bautista Diamante, a cargo de la compañía de Antonio de Escamilla para celebrar los años de la Reina Madre el 22 de diciembre 1675. A pesar de no contar con el título de esta comedia, Stein ${ }^{56}$ indica que en esta fecha se representó El Faetonte ${ }^{57}$ con música de Juan Hidalgo. Por su parte, Shergold

53 Shergold y Varey, 1982, p. 67.

54 Cruickshank en la edición de La púrpura de la rosa, p. 522. Compárense los 73 reales y medio con los 24 y medio que se pagan en 1676 «Al que tenía la segunda jornada de Amado y aborrecido, porque la diera» (Shergold y Varey, 1982, p. 67).

55 1982, pp. 64-66.

56 1993, p. 349.

57 Neumeister, 1978 , p. 353b y 2000, p. 313, ofrece la misma fecha. 
y Varey, que dan la nómina de gastos de las comedias que se representaron el 18 de enero de 1676 y los días posteriores, no recogen ninguna noticia que se refiera explícitamente a El Faetonte ${ }^{58}$. En cambio, Subirats ${ }^{59}$ menciona una representación el 1 de febrero de ese año 1676, aunque sin indicar lugar y compañía encargada.

El Faetonte volvió a montarse en el mes de diciembre de 1679 con motivo del cumpleaños de Mariana de Austria. Los gastos de la fiesta, publicados también por Shergold y Varey ${ }^{60}$, revelan las fechas tanto de los ensayos como de la representación e igualmente el lugar en el que se celebró: «Relazion de los gastos hechos y que se consideran necesarios para la comedia del Faeton que se represento en el Salon del Buen Retiro a la zelebridad de los años de la Reyna Madre nuestra Señora el dia 22 de diziembre del año pasado de 1679 y se empezo a ensayar el dia 4 de diziembre del dicho año». La compañía encargada de la fiesta fue la de Manuel Vallejo ${ }^{61}$; los nombres de sus integrantes y, en varios casos, el papel que se les otorgó ha quedado igualmente recogido en la lista de los gastos. La obra de Calderón estuvo acompañada en esta ocasión de nuevas piezas breves que no coinciden con las de 1662. Se trata de "el bayle de La gayta gallega", "el entremes de El retrato de Juan Rana» y «el fin de fiesta de Las naciones", por los que se pagaron 600 reales a Manuel Vallejo y Antonio de Escamilla $^{62}$.

En el mismo expediente se indica además que a don Pedro Calderón se le pagaron 3.300 reales por «hauer compuesto la comedia y hecho la loa» ${ }^{63}$. Ello ha motivado cierta controversia entre los investigadores que han estudiado El Faetonte y, en concreto, esta reposición. Las acotaciones que presenta la edición de Vera Tassis, que difieren de

${ }^{58}$ Las comedias que se representaron el 18 de enero de 1676 y los días posteriores fueron: Amado y aborrecido y El caballero de Olmedo; en los Carnavales siguientes se añadieron Del mal lo menos, Los tres mayores prodigios y El pastor Fido (Shergold y Varey, 1982, p. 66 y 71).

${ }^{59}$ Subirats, 1977, p. 443. Remite el origen de la noticia al legajo 666 del Archivo de Palacio, que es el mismo sobre el que trabajaron Shergold y Varey.

60 1982, pp. 90-98. La noticia de representación la ofrece también Subirats, 1977, p. 443.

61 «A la compañia de Manuel Vallejo, por la fiesta y haber dejado de representar ocho dias». (Shergold y Varey, 1982, p. 94).

62 Shergold y Varey, 1982, p. 93.

63 Shergold y Varey, 1982, p. 97. 
las publicadas en 1672 y 1674 , ofrecen alguna coincidencia con el material que se utilizó para las tramoyas de 1679 , referido en la lista de los gastos ${ }^{64}$, lo que condujo a Shergold a afirmar que el amigo de Calderón había utilizado para su edición «the original edition of 1672 - or a manuscript copy of it - as adapted for production in 1679 under Calderón's own supervision» ${ }^{65}$. Proponía, por lo tanto, que Calderón había adaptado la comedia a unas nuevas circunstancias de representación casi veinte años despues de haber compuesto el original y que este nuevo texto había sido el empleado por Vera Tassis para su edición.

En el año 2002 Lobato rebatió de forma convincente la afirmación de Shergold, demostrando que para la representación de 1679 no hubo reescritura del texto inicial, sino que se montó a partir del texto de la edición autorizada por el dramaturgo, la de $1674^{66}$, quien «dio por buenas las tramoyas de Caudí que, respetando el texto, planteaban una complejidad mayor que la de la primera puesta en escena, como testimonian las acotaciones que han llegado a nosotros en la edición de Vera Tassis de $1688 »^{67}$. El «mayor amigo» de Calderón adoptó para las acotaciones de su edición la indicación de las tramoyas empleadas en 1679, acaso porque asistió a la fiesta o bien porque hubiese llegado a sus manos una memoria de las apariencias empleada en aquella ocasión, pero siempre sobre la base del texto publicado en 1674. Lo que no tuvo fue un manuscrito con una versión refundida, sin duda porque no la hubo. El cotejo realizado por nosotros muestra que Vera siguió la edición de 1674, corrigiéndola según sus hábitos y costumbres.

En fin, en la década siguiente El Faetonte siguió presente en la escena fuera de la Corte madrileña. El DICAT recoge una noticia de la representación de esta pieza a cargo de las compañías de Ángela León y Agustín Manuel el 3 o el 7 de diciembre de 1681 en Valencia; de nuevo en el DICAT se encuentra otra noticia que indica que la comedia se montó el 7 de mayo de 1690 en el Real Salón de Palacio

${ }^{64}$ Ver los gastos de las tramoyas en Varey y Shergold, 1982, pp. 96-97.

65 Shergold, 1955, p. 214. Ver también Shergold, 1967, p. 342.

66 Entre los «Gastos de la casa de los ensayos» que publican Varey y Shergold (1982, pp. 90-91) se encuentra un pago de 16 reales «Por un libro de comedias» que bien podría ser un ejemplar de la edición de 1674 .

67 Lobato, 2002a, p. 356. 
de Valladolid por las compañías de María Álvarez y Gregorio Antonio y, en fin, Stein ${ }^{68}$ señala una última representación el 22 de diciembre de 1697 sin indicar lugar o compañía encargada.

Al lado de las citadas vale la pena recordar también la representación del melodrama italiano El Fetonte, celebrada en noviembre de 1685 con motivo del cumpleaños de Carlos II, que Profeti ha descrito como "una filiazione diretta da una "fábula" calderoniana, El Faetonte, con importante presenza musicale, a un testo per musica italiano: Il Fetonte» ${ }^{69}$. El libreto, de Giuseppe Domenico de Totis, se imprimió en Nápoles en el mismo año que se representó con dedicatoria al virrey de Nápoles, don Gaspar de Haro y Guzmán ${ }^{70}$.

Termina así la vida escénica de El Faetonte en el siglo xviI, por lo que hasta hoy sabemos. Parece claro ya que su estreno se produjo el 20 de febrero de 1662 y que Calderón debió de escribirla poco antes, lo mismo que la loa que la precedió. Resta ahora el análisis de los problemas textuales, que permitirán contar con un texto muy próximo al que en efecto oyó la corte aquel día. Pero ese es un trabajo que ha de quedar para una próxima ocasión.

68 1993, p. 349.

69 Profeti, 2002, p. 348. Ver Profeti, 2009, pp. 147-148, para una explicación de los distintos modos de adaptar al italiano comedias españolas; ese proceso rara vez se hacía sobre la fuente original, sino más bien sobre traducciones intermedias, por ejemplo, francesas.

${ }^{70}$ A esta representación se han referido D’Antuono, 2000 y Profeti, 2002 y 2009. 


\section{BIBLIOGRAFÍA}

Borrego Gutiérrez, E., Un poeta cómico en la corte. Vida y obra de Vicente Suárez de Deza, Kassel, Reichenberger, 2002.

Buezo, C., La mojiganga dramática de la fiesta al teatro, Kassel, Reichenberger, 1993, 2 vols.

Calderón de la Barca, P., Celos aun del aire matan, ed. M. D. Stroud, San Antonio, Trinity University Press, 1981.

- Celos aun del aire matan, ed. E. Rull Fernández, Madrid, UNED, 2004.

- Comedias, ed. J. E. Hartzenbusch, Madrid, 4 vols., 1848-1850 (BAE, vols. VII, IX, XII y XIV).

- Comedias, II. Segunda Parte de Comedias, ed. S. Fernández Mosquera, Madrid, Biblioteca Castro, Fundación José Antonio de Castro, 2007.

- Comedias, III. Tercera Parte de Comedias, ed. D. W. Cruickshank, Madrid, Biblioteca Castro, Fundación José Antonio de Castro, 2007.

- Comedias, IV. Cuarta Parte de Comedias, ed. S. Neumeister, Madrid, Biblioteca Castro, Fundación José Antonio de Castro, 2010.

- El Faetonte, ed. R. Maestre, Madrid, Comunidad de Madrid, Consejería de Educación y Cultura, 1996.

- La púrpura de la rosa, ed. A. Cardona, D. Cruickshank y M. Cunningham, Kassel, Reichenberger, 1990.

- Las manos blancas no ofenden (dos textos de una comedia), ed. Á. Martínez Blasco, Kassel, Reichenberger, 1995.

- Obras completas. Dramas, ed. Á. Valbuena Briones, Madrid Aguilar, 1959 y 1966.

Checa, F., El Real Alcázar de Madrid, Madrid, Comunidad de Madrid / Nerea, 1994.

Cienfuegos Antelo, G., El teatro breve de Francisco de Avellaneda: estudio y edición, Madrid, Fundación Universitaria Española, 2006.

Contreras, J., Carlos II el Hechizado, Madrid, Temas de Hoy, 2003.

Cotarelo y Mori, E., Historia de la zarzuela, o sea el drama lírico en España, desde su origen a fines del siglo XIX, Madrid, Tipografia de Archivos, 1934.

- Ensayo sobre la vida y obras de d. Pedro Calderón de la Barca, Madrid, Tipografia de la Revista de Archivos, Bibliotecas y Museos, 1924; edición facsímil al cuidado de I. Arellano y J. M. Escudero, Madrid / Frankfurt, Iberoamericana / Vervuert, 2001.

CRUickshank, D. W., "The textual criticism of Calderón's comedias: a survey», en The textual criticism of Calderón's comedias, ed. D. W. Cruickshank y J. E. Varey, P. Calderón de la Barca, Comedias. A facsimile edition prepared by D. W. Cruickshank and J. E. Varey with textual and critical studies, London, Gregg International / Tamesis, 1973, vol. I, pp. 1-53. 
— «Calderón de la Barca, Pedro», en el Diccionario filológico de literatura española. Siglo XVII, dirigido por Pablo Jauralde, en prensa.

Cruickshank, D. W. y J. E. Varey, Comedias. A facsimile edition prepared by D. W. Cruickshank and J. E. Varey with textual and critical studies, London, Gregg International / Tamesis, 1973, vols. X y XI.

Chaves Montoya, M. T., El espectáculo teatral en la corte de Felipe IV, Madrid, Ayuntamiento de Madrid, Área de Gobierno de las Artes, 2004.

D’Antuono, N. L., "Calderón a la italiana: El hijo del sol, Faetón en la corte virreinal de Nápoles en 1685", en El texto puesto en escena. Estudios sobre la comedia del Siglo de Oro en honor a Everett $W$. Hesse, ed. B. Mujica y A. K. Stoll, London, Tamesis, 2000, pp. 22-32.

Díez Borque, J. M., «Noticias que del teatro cortesano y su aparato da el avisador Barrionuevo», Cuadernos de Teatro Clásico, 8 («La puesta en escena del teatro clásico»), 1995, pp. 269-298.

Fernández Mosquera, S., «El significado de las primeras fiestas cortesanas de Calderón de la Barca», en Calderón y el pensamiento ideológico y cultural de su época. XIV Coloquio Anglogermano sobre Calderón, ed. M. Tietz y G. Arnscheidt, Stuttgart, Franz Steiner (Archivum Calderonianum, 11), 2008, pp. 209-232.

FARrÉ, J., «Aproximaciones al itinerario de un género teatral en el siglo XVII, a propósito de las loas palaciegas de Calderón de la Barca», Anuario Calderoniano, 2, 2009, pp. 143-179.

Ferrer, T., Diccionario biográfico de actores del teatro clásico español (DICAT), Kassel, Reichenberger, 2008 (con un CD-rom).

Greer, M. R. y J. E. VArey, El teatro palaciego en Madrid: 1586-1707. Estudio y documentos, Madrid, Támesis, 1997.

Hilborn, H. W., A Chronology of the Plays of D. Pedro Calderón de la Barca, Toronto, University of Toronto Press, 1938.

Iglesias Fejoo, L., "El romance de Góngora en El príncipe constante de Calderón", Rilce, 26, 1, 2010 ("Rompa con dulces números el canto": Homenaje a Antonio Carreño), pp. 74-96.

Loвato, M. L., «Un actor en Palacio: Felipe IV escribe sobre Juan Rana», Cuadernos de Historia Moderna, 23, 1999, pp. 79-111.

- «Calderón, cisne del Manzanares: loas cortesanas y conciencia artística», Bulletin of Spanish Studies, 77, 1, 2000, pp. 357-389.

- «Calderón en los sitios de recreación del Rey: esplendor y miserias de escribir en palacio», en Calderón: sistema dramático y técnicas escénicas, Actas de las XXIII Jornadas de teatro Clásico de Almagro, ed. F. B. Pedraza Jiménez, R. González Cañal y E. Marcello, Almagro, Ediciones de la Universidad de Castilla-La Mancha, 2001, pp. 187-222.

- «Espacio y conflicto o el conflicto del espacio en la puesta en escena de El hijo del sol, Faetón, de Calderón», en Homenaje a Frédéric Serralta. El es- 
pacio y sus representaciones en el teatro español del Siglo de Oro, ed. F. Cazal, Ch. González y M.Vitse, Madrid / Frankfurt, Iberoamericana / Vervuert, 2002a, pp. 337-358.

- «Fiestas teatrales al infante Felipe Próspero (1657-1661) y edición del baile "Los Juan Ranas" (XI-1658)", Scriptura, 17, 2002b, pp. 227-261.

Maura, Duque de, Vida y reinado de Carlos II, Madrid, Aguilar, 1990, nueva ed. con prólogo de P. Gimferrer.

Morley, S. G. y C. Bruerton, Cronología de las comedias de Lope de Vega, Madrid, Gredos, 1968.

Neumeister, S., Mythos und Repräsentation. Die mythologischen Festpiele Calderóns, München, Wilhelm Fink, 1978. Traducción: Mito clásico y ostentación, Kassel, Reichenberger, 2000.

Orso, S. N., Philip IV and the Decoration of the Alcázar of Madrid, Princeton, Princeton University Press, 1986.

PAris, P., «La mythologie de Calderón. Apolo y Climene. El hijo del Sol, Faetón», en Homenaje ofrecido a Menéndez Pidal, Madrid, Hernando, 1925, I, pp. 557-570.

Paz y Mélia, A. y J. PAz, Catálogo de las piezas de teatro que se conservan en el Departamento de Manuscritos de la Biblioteca Nacional, Madrid, Blass S. A. Tipográfica, t. I, 1934.

Pellicer, C., Tratado histórico sobre el origen y progresos de la comedia y del histrionismo en España, Madrid, 1804, 2 vols.

Pérez Pastor, C., Documentos para la biografía de D. Pedro Calderón de la Barca, Madrid, 1905, vol. I (único publicado).

Profeti, M. G., "Calderón in Italia: testi per musica», en Giornate Calderoniane. Calderón 2000. Atti del Convegno Internazionale, Palermo 14-17 Diciembre 2000, ed. E. Cancelliere, Palermo, Flaccovio Editore, 2002, pp. 347-360.

- Commedie, riscritture, libretti: la Spagna e l'Europa, colección Commedia aurea spagnola e pubblico italiano, Firenze, Alinea, vol. VII, 2009.

ReICHENBER Ger, K. y R., Manual bibliográfico calderoniano, Kassel, Verlag Thiele and Schwarz, t. I y III, 1979.

Romero Blázquez, C., Estudio, edición crítica y anotación de dos comedias palatinas de Calderón de la Barca: La señora y la criada y El acaso y el error, Tesis doctoral inédita, Pamplona, Universidad de Navarra, 2007.

SÁnchez-Arjona, J., Noticias referentes a los Anales del teatro en Sevilla, Sevilla, 1898; ed. facsímil, Sevilla, Ayuntamiento, 1994.

SÁnChez Mariana, M., "Un manuscrito calderoniano desconocido (con una digresión sobre los autógrafos de Matos Fragoso)», Revista de Literatura, 46, 1984, pp. 121-130.

Sher gold, N. D., "Calderón and Vera Tassis», Hispanic Review, 23, 3, 1955, pp. 212-218.

- A History of Spanish Stage, Oxford, Oxford University Press, 1967. 
Shergold, N. D., y J. E. Varey, Los autos sacramentales en Madrid en la época de Calderón. 1637-1681. Estudio y documentos, Madrid, 1961.

- Representaciones palaciegas 1603-1699. Estudio y documentos. London, Tamesis, 1982.

Stein, L. K., Songs of Mortals, Dialogues of the Gods. Music and Theatre in Seventeenth-Century Spain, Oxford, Clarendon Press, 1993.

SuÁrez de Deza, V., Teatro breve, Kassel, Reichenberger, 2000, 2 vols.

Subirá, J., Celos aun del aire matan. Ópera del siglo XVII. Texto de Calderón y música de Juan Hidalgo, Barcelona, Institut d'Estudis Cataláns / Biblioteca de Catalunya, 1933.

- El gremio de representantes españoles y la Cofradía de Nuestra Señora de la Novena, Madrid, CSIC, 1960.

Subirats, R., "Contribution a l'établissement du répertoire teatral a la Cour de Philippe et Charles II», Bulletin Hispanique, 79, 1977, pp. 401-479.

Tobar, M. L. (ed.), Atti della tavola rotonda sulla singolarità storica e estetica di La Púrpura de la rosa di Calderón de la Barca, Messina, Armando Siciliano, 2000.

Varey, J. E., Historia de los títeres en España, Madrid, Revista de Occidente, 1957.

Varey, J. E. y N. D. Shergold, Teatros y comedias en Madrid: 1651-1665. Estudio $y$ documentos, London, Tamesis, 1973.

- (ed.), Genealogía, origen y noticias de los comediantes de España, London, Tamesis, 1985. 